\title{
Time optimal control of one and double one winding VCM motor"
}

\author{
WOJCIECH KOLTON \\ Department of Mechatronics, Faculty Of Electrical Engineering \\ Silesian University of Technology \\ Krzywoustego 2, 44-100 Gliwice, Poland \\ e-mail: wojciech.kolton@polsl.pl
}

(Received: 10.12.2012, revised: 09.09.2013)

\begin{abstract}
This article presents the time optimal control system adopted to control double winding VCM motor. This kind of control is widely used in hard disk drive servo for head positioning. Mathematical model of double winding VCM motor is presented, and its implementation in MATLAB/Simulink is shown. The extended time optimal control algorithm is implemented on dSpace DS1104 board. The results obtained from simulation and real measurements are compared and discussed.
\end{abstract}

Key words: time optimal control, VCM motor, mass storage devices

\section{Introduction}

The hard disk drive technology is still growing rapidly, despite solid state drives occurring in the market. If we focus on last twelve years the data areal density increased seventy five times, and now in commercial product (hard disk drives manufactured by Western Digital or Seagate) it reaches the value of $625 \mathrm{~Gb} / \mathrm{in}^{2}$ (Fig. 1). Such a high value of data areal density result in high density of data track $[1,2]$, making its width very small (about tenths nanometers). It is necessary to make changes in head positioning system [3, 4], increasing the number of motors in its kinematic structure $[5,6]$ which allows for construct the very precise servo system. Also it is possible to construct VCM motor [7] and propose the new concept of control, which also may be helpful to meet high data areal densities demands. The first main winding of armature ensures the high angular acceleration in the search phase and the second auxiliary allows get precision tracing of data track in tracking phase. In addition, it would serve to angular speed measurements, and could be used for elimination of the vibration generated by rotating spindle system. In this article a prototype system for positioning heads equipped with prototype of VCM motor with double windings is presented.

\footnotetext{
* This is extended version of a paper which was presented at the XV Jubileuszowe Sympozjum „Podstawowe Problemy Energoelektroniki, Elektromechaniki i Mechatroniki” PPEEm, 2012.
} 


\section{Model of two armature VCM motor}

Assembled two armature VCM motor is presented in Figure 2. The real VCM motor consists of two armature windings (1), situated one above another, flexible printed circuit (2). The rest of head positioning system components depicted in Figure 2. are as follows: coil holder (3), base for bearing housing (4), single E-block arm (5).

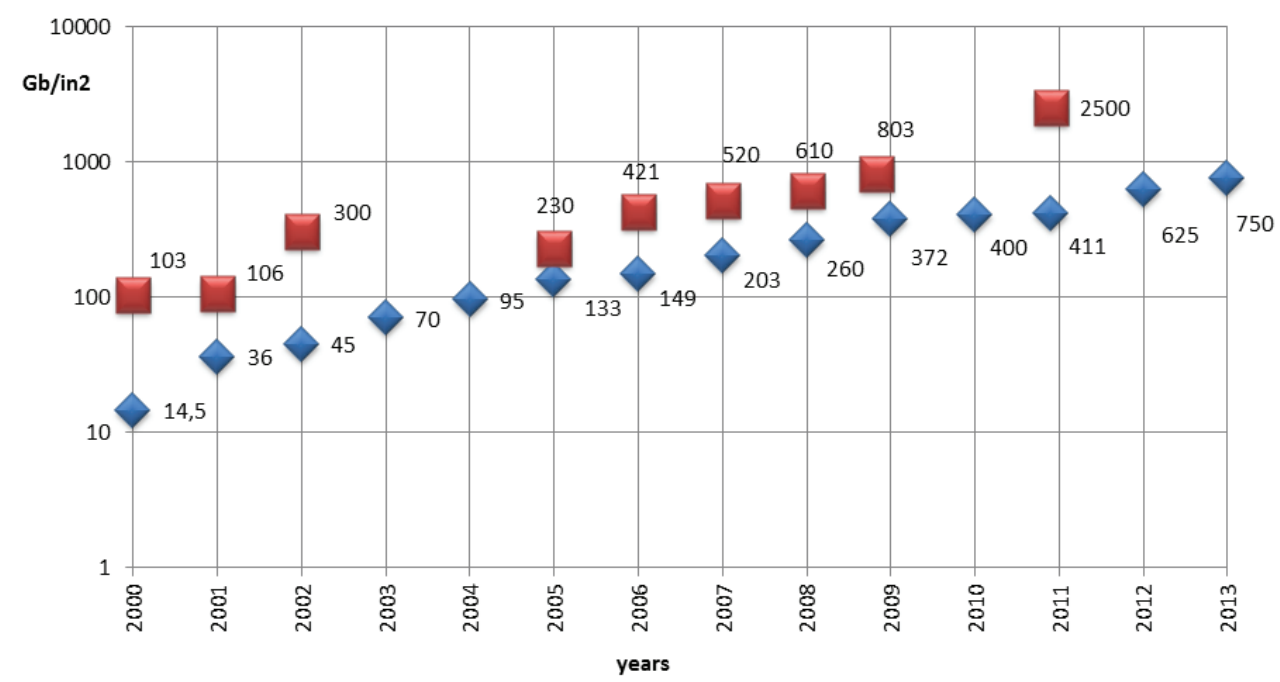

Fig. 1. Data areal densities increase over last 12 years, blue marks represent commercial products, red marks represent values reached in laboratory condition

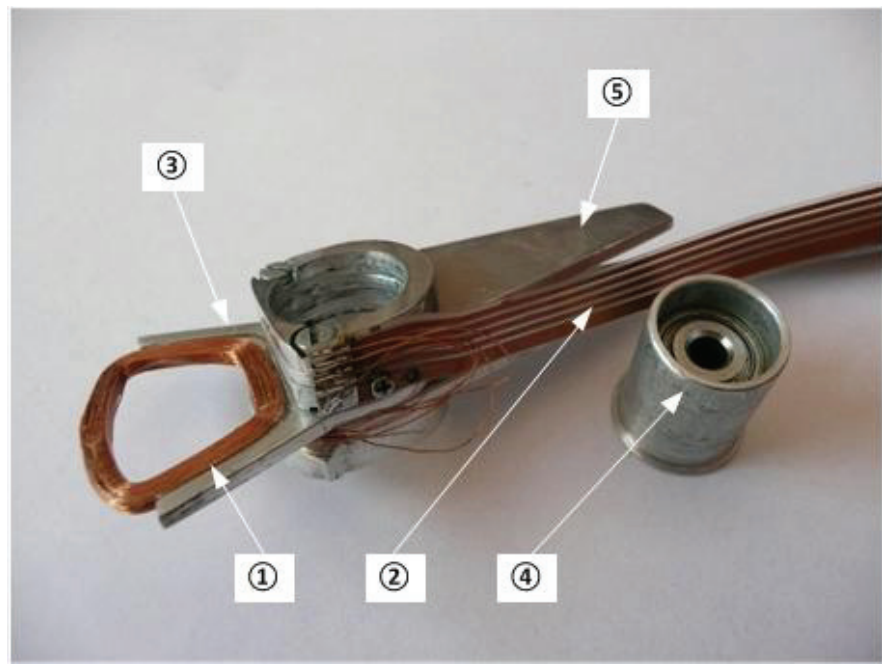

Fig. 2. Assembled double winding VCM motor and the components of head positioning system 
For double winding VCM motor, it can be represented by the equivalent scheme presented in Figure 3. This motor is composed of two electrical circuits RLE electromagnetically coupled with each other, and the mechanical system is represented by one mass (denoted by $J_{\mathrm{b}}$ ) with only one degree of freedom. The mechanical system is representing (in the simplest possible case) the system inertial masses (the sum of inertial mass of the E-block, armature winding, slides suspensions, slides and heads) and the elastic element (representing the stiffness of the flexible printed circuit, including voltage supply inlet of armature circuit) [7].

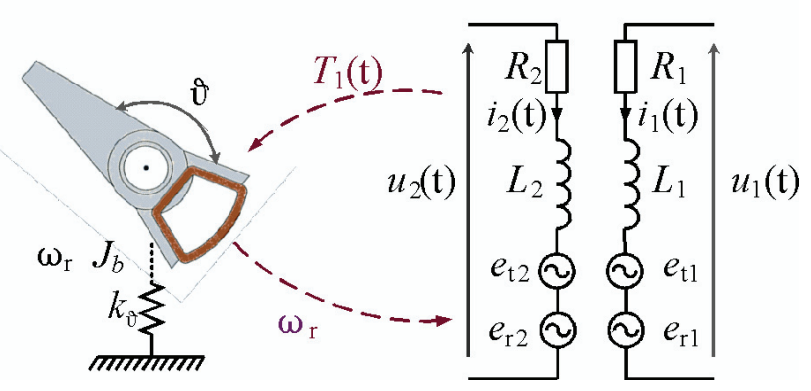

Fig. 3. Schematic representation of two winding VCM motor

The equivalent circuit model of double winding VCM motor consists of armature resistances $R_{1}$ and $R_{2}$, armature self inductions $L_{1}$ and $L_{2}$. The $e_{\mathrm{t} 1}$ and $e_{\mathrm{t} 2}$ representing induced voltages in armature windings, and $e_{\mathrm{r} 1}, e_{\mathrm{r} 2}$ representing back electromotive force voltage. $u_{1}(t)$, $u_{2}(t)$ and $i_{1}(t), i_{2}(t)$ power supply voltages and windings currents, $T_{\mathrm{e} 1}, T_{\mathrm{e} 2}-$ electromagnetic torque generated separately by two armatures, $\vartheta, \omega_{\mathrm{r}}$ - angular displacement and angular speed of the rotor, $k_{9}, J_{\mathrm{b}}$ - stiffness of flexible printed circuit and mass moment of inertia (of all mechanical components of positioning system). For circuit presented in Figure 3 the following differential equation can be written:

$$
\left\{\begin{array}{l}
\frac{\mathrm{d}}{\mathrm{d} t} i_{1}(t)=\frac{L_{2}}{\sigma_{\mathrm{V}}}\left(u_{1}(t)-R_{1} i_{1}(t)-k_{\mathrm{e} 1}(\vartheta) \omega(t)\right)-\frac{L_{m}}{\sigma_{\mathrm{V}}}\left(u_{2}(t)-R_{2} i_{2}(t)-k_{\mathrm{e} 2}(\vartheta) \omega(t)\right) \\
\frac{\mathrm{d}}{\mathrm{d} t} i_{2}(t)=-\frac{L_{m}}{\sigma_{\mathrm{V}}}\left(u_{1}(t)-R_{1} i_{1}(t)-k_{\mathrm{e} 1}(\vartheta) \omega(t)\right)+\frac{L_{1}}{\sigma_{\mathrm{V}}}\left(u_{2}(t)-R_{2} i_{2}(t)-k_{\mathrm{e} 2}(\vartheta) \omega(t)\right) \\
\frac{\mathrm{d}}{\mathrm{d} t} \omega(t)=J_{\mathrm{b}}^{-1}\left(k_{\mathrm{t} 1}(\vartheta) i_{1}(t)+k_{\mathrm{t} 2}(\vartheta) i_{2}(t)-k_{\vartheta} \vartheta(t)-b \omega(t)\right) \\
\frac{\mathrm{d}}{\mathrm{d} t} \vartheta(t)=\omega(t),
\end{array}\right.
$$

where $L_{m}$ - mutual inductances between armature coils, $\sigma_{\mathrm{V}}=L_{1} L_{2}-L_{m}^{2}, b$ - mechanical dumping, $t$ - time.

The equations for back electromotive force voltages constant $k_{\mathrm{e} 1,2}$ and torque constant $k_{\mathrm{t} 1,2}$ can be expressed by: 


$$
k_{\mathrm{e} 1,2}=k_{\mathrm{t} 1,2}=2 N_{1,2} B\left(2 r l+l^{2}\right),
$$

where $N_{1,2}$ - number of turns of armature coils, $B$ - average value of magnetic flux density in air gap, $r$ - coils rotations radius, $l$ - length of one side of coil in magnetic field.

Equations which describe torque components and back electromotive force voltage for single armature coil are as follows:

$$
\begin{aligned}
& T_{\mathrm{e} 1}=2 N_{1} B\left(2 r l+l^{2}\right) i_{1}(t), \\
& e_{\mathrm{r} 1}=2 N_{1} B\left(2 r l+l^{2}\right) \omega_{r} .
\end{aligned}
$$

\section{Structure of the time optimal control of VCM motor with one winding}

The control law under time optimal control (TOC) algorithm of one winding VCM motor [8] can be described the following, nonlinear equation:

$$
\hat{i}=i_{\max } \operatorname{sgn}\left(\sqrt{2 \frac{k_{\mathrm{t}} i_{\max }}{J_{b}}\left(\vartheta_{f s}-\vartheta\right)}-\omega\right),
$$

where $\omega$ - angular velocity of the motor, $i_{\max }$ - maximum allowable current values, $\vartheta$ - angular position of VCM motor, $\vartheta_{f s}$ - forcing signal, $\hat{i}$ - armature current under time optimal control.

For basic investigation of TOC control system, the control scheme and VCM motor model was implemented in MATLAB/Simulink environment. Block scheme of TOC of single winding motor is presented in Figure 4.

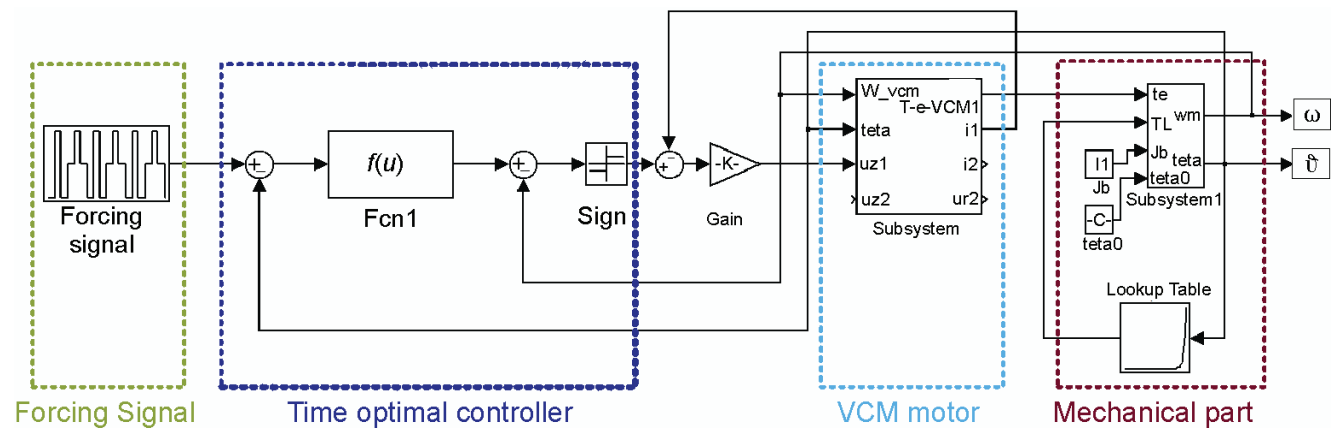

Fig. 4. Implementation of time optimal control of exemplary single armature VCM motor

The implementation of time optimal control algorithm and VCM motor model which is presented in Figure 4 can be divided into 4 blocks. The first one, "Forcing signal" is used to inflict the head arm angular displacements in sequence shown in Figure 5. The second block, 
"Time optimal controller" implements control algorithm according to Equation 5. The third block "VCM motor" is double winding VCM motor with one winding connected to the supply source (output of the controller). The last block "Mechanical part" represents the mechanical part of the positioning system like stiffness of flexible printed circuit and mass moment of inertia.

Fig. 5. Time plot of forcing signal

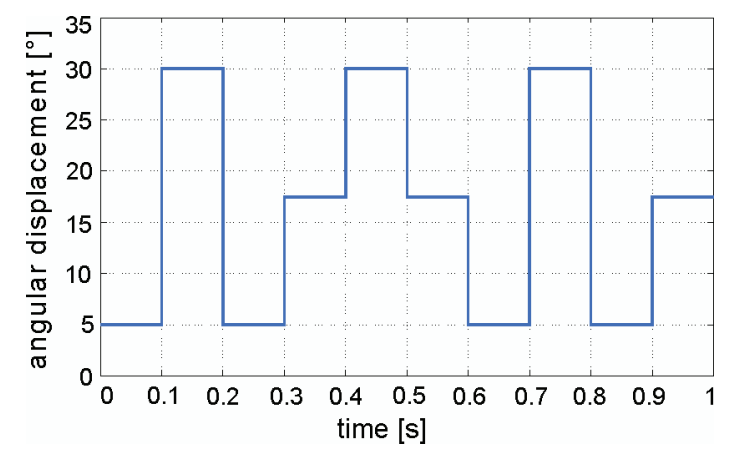

The software implementation of the time optimal control is presented in Figure 6 presented, and it operates with a laboratory test bench presented in Figure 7 . The laboratory test bench consists of dSpace 1104 signal processors card (implementation of time optimal controller), is also equipped with a Keyence LK-G152 (1) laser displacement meter for indirect measurements of E-block angular displacement, transconductance amplifier (2), PC and prototype of VCM motor (3).

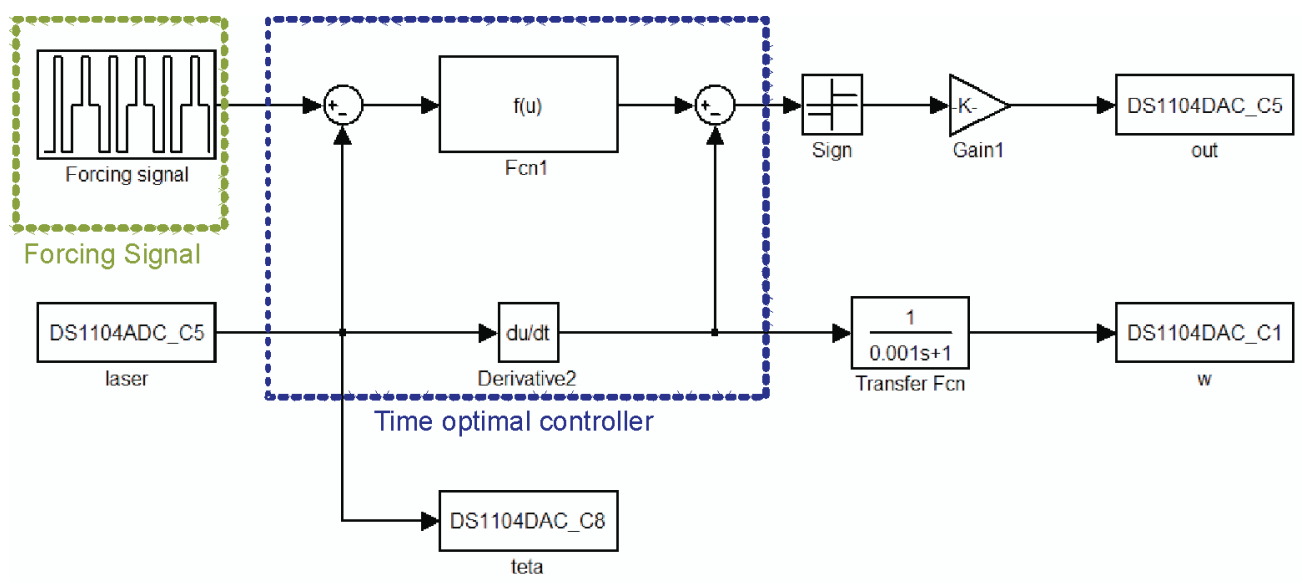

Fig. 6. The controller of time optimal control implemented on the signal processor card dSpace 1104

The implementation of time optimal control presented in figure above includes two fundamental parts: "Time optimal controller" and "Forcing Signal" which performs the same tasks as in the case of "Implementation of time optimal control" shown in Figure 4. The DSC1104_ADC_C5 block is used to measure angular displacement using a laser sensor. The 
last two blocks are outputs of dSpace cards. They are connected to an external oscilloscope (Tektronix TDS3054) which records the angular displacement waveforms (DS1104DAC_08) and the angular speeds waveforms (DS1104DAC_C5).

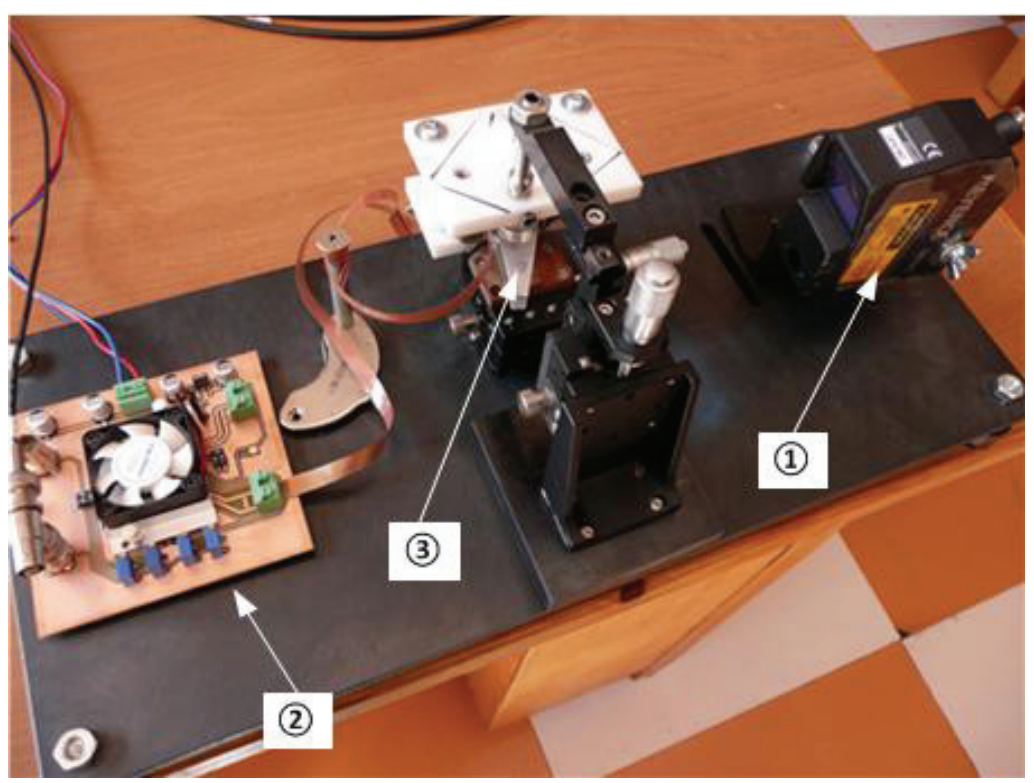

Fig. 7. Test bench for investigations of VCM motor time optimal control

\section{Research results of one winding VCM motor}

The exemplary results of the sequential angular motion of the head arm obtained by the simulation and the measurement are shown in Figures 8 and 9.

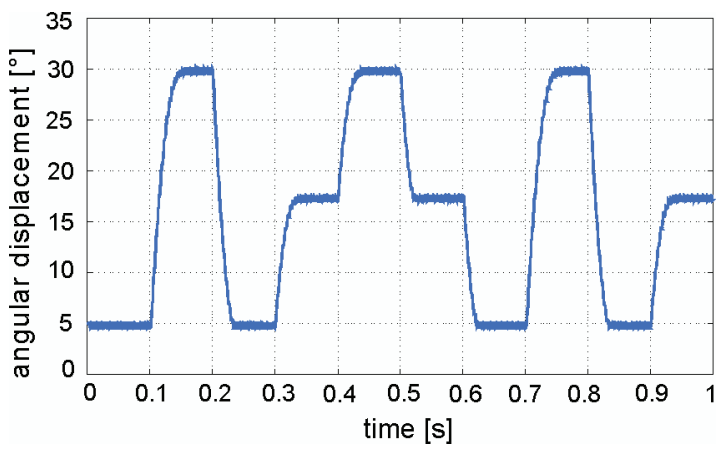

Fig. 8. Angular displacement of E-block, the result of simulation 
Fig. 9. Angular displacement of E-block, the result of the measurements

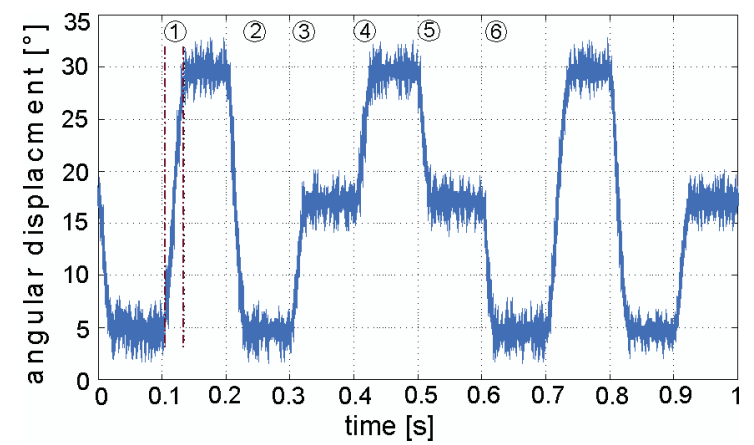

Dividing sequential angular displacement of the E-block into 6 sections and then measuring control times (the time after E-block reach the set value), the comparison of the results obtained from simulation and from the test bench is possible. Comparison is presented in Table 1. The difference between simulation and measurements does not exceed $15.4 \%$.

Table 1. Control time

\begin{tabular}{|c|c|c|c|c|c|c|c|c|c|c|c|c|}
\hline \multirow{2}{*}{ Section } & \multicolumn{2}{|c|}{ (1) } & \multicolumn{2}{|c|}{ (2) } & \multicolumn{2}{|c|}{ (3) } & \multicolumn{2}{|c|}{ (4) } & \multicolumn{2}{|c|}{ (5) } & \multicolumn{2}{|c|}{ (6) } \\
\hline & $t_{\text {sym }}$ & $t_{m e s}$ & $t_{\text {sym }}$ & $t_{m e s}$ & $t_{\text {sym }}$ & $t_{m e s}$ & $t_{\text {sym }}$ & $t_{m e s}$ & $t_{\text {sym }}$ & $t_{m e s}$ & $t_{\text {sym }}$ & $t_{m e s}$ \\
\hline Time $[\mathrm{ms}]$ & 32 & 28 & 32 & 29 & 21 & 19 & 15 & 13 & 15 & 14 & 23 & 20 \\
\hline$\delta[\%]$ & \multicolumn{2}{|c|}{14.3} & \multicolumn{2}{|c|}{10.3} & \multicolumn{2}{|c|}{10.5} & \multicolumn{2}{|c|}{15.4} & \multicolumn{2}{|c|}{7.1} & \multicolumn{2}{|c|}{15.0} \\
\hline
\end{tabular}

where $t_{\text {sym }}$ is the control time in simulation, $t_{m e s}$ is the control time of the real object

The time optimal control is the relay type of control algorithm. It works on the principle of changing the direction of electric current of the VCM motor. Effect of this switching is an increasing angular velocity of the E-block, and slowing down to zero after the direction of the current change. This causes the generation of typical triangle shapes in angular velocity curves, which are shown in Figures 10 and 11. The rising edge of the triangle represents angular speed during acceleration and falling edge represents deceleration of VCM motor.

Fig. 10. The angular velocity of the E-block, the results of simulation

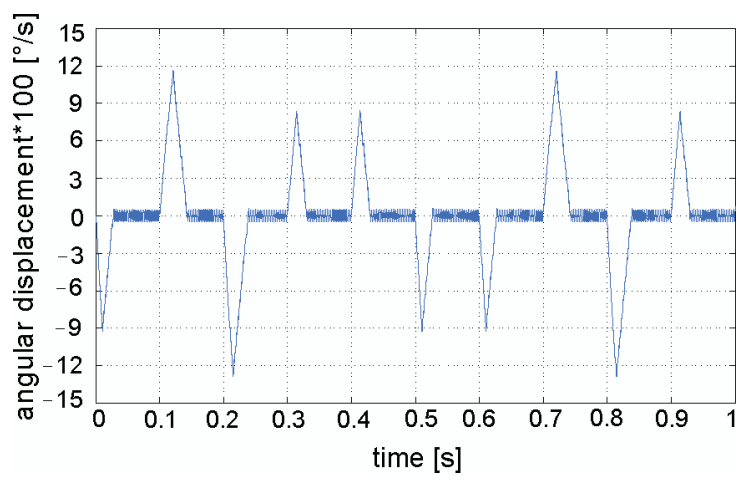




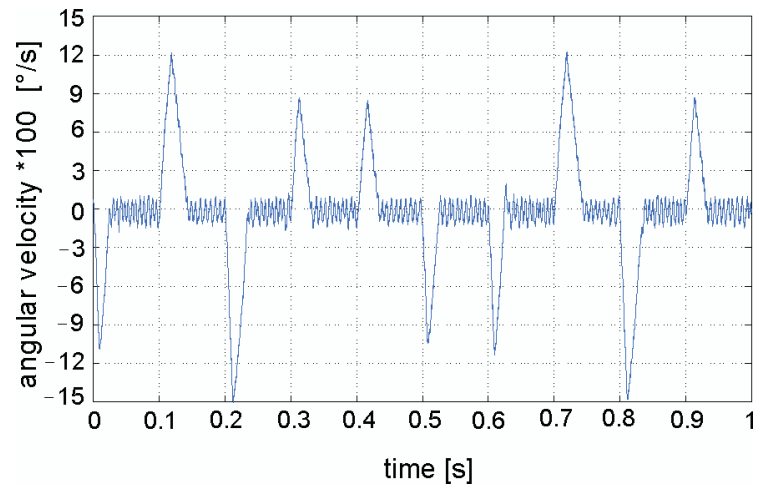

Fig. 11. The angular velocity of the E-block, the results of the measurements

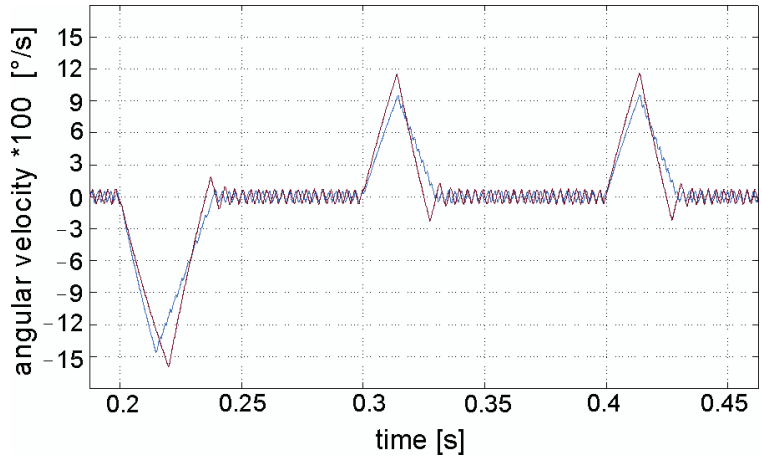

Fig. 12. Chattering phenomenon: blue curve represents good matched control, red curve represents wrong matched control

The main disadvantage of time optimal control is occurrence of the chattering phenomenon, which is caused by fast switching current direction in VCM armature, when the Eblock reaches the set position. This switching can be seen like the vibration of the VCM motor. If time optimal control is properly matched the amplitudes of these oscillations are constant and uniform, because the speed of the E-block is equal to zero when the desired angular position is reached. Figure 12 (blue curve) shows the magnified time period from Figure 10 where the chattering phenomenon occurred. The amplitudes of oscillations are constant because the controller is properly matched. The second red curve represents the simulated angular speed with wrong matched controller.

\section{Structure of the time optimal control of double winding VCM motor with second winding used for position and velocity estimation}

The time optimal control of VCM motor with two armatures is shown in Figure 13. It includes the same: control block "Time optimal controller", signal block "Forcing Signal" and a block representing the mechanical and electrical parts as in the case of control scheme 
shown in Figure 4. The software implementation is presented in Figure 14. The block "DS1104ADC_C5" is the input of the induced voltage in the second winding, the "DS1104DAC_C1" and "DS1104DAC_C2" are outputs of estimated angular velocity and angular position. The other blocks perform the same function as in the Figure 4.

The VCM motor has a second coil, which is short circuited by resistor. In the simplest case voltage drop on short circuiting resistor (omitting influence of voltage drop on second armature inductances an internal resistance) is proportional to induced voltage resulting from rotor motion. Basing on this measured voltage it is possible to calculate the real value of angular speed and position of the E-block. It can be done by following formula:

$$
\begin{gathered}
\omega_{\mathrm{es}} \approx \frac{-u_{\mathrm{r} 2}}{2 N_{2} B_{\text {averange }}\left(2 r l+l^{2}\right)}, \\
\vartheta_{e s}=\int \omega_{\mathrm{es}} \mathrm{d} t+\vartheta_{0},
\end{gathered}
$$

where: $\omega_{\mathrm{es}}$ is the estimation of angular velocity, $u_{\mathrm{r} 2}$ is the induced voltage, $N_{2}$ is the number of coil turns of second winding, $l$ is the length of the side of the winding, $\vartheta_{e s}$ is the estimate of angular position, $\vartheta_{0}$ is the initial angular position, $B_{\text {averange }}$ is the average magnetic flux density.

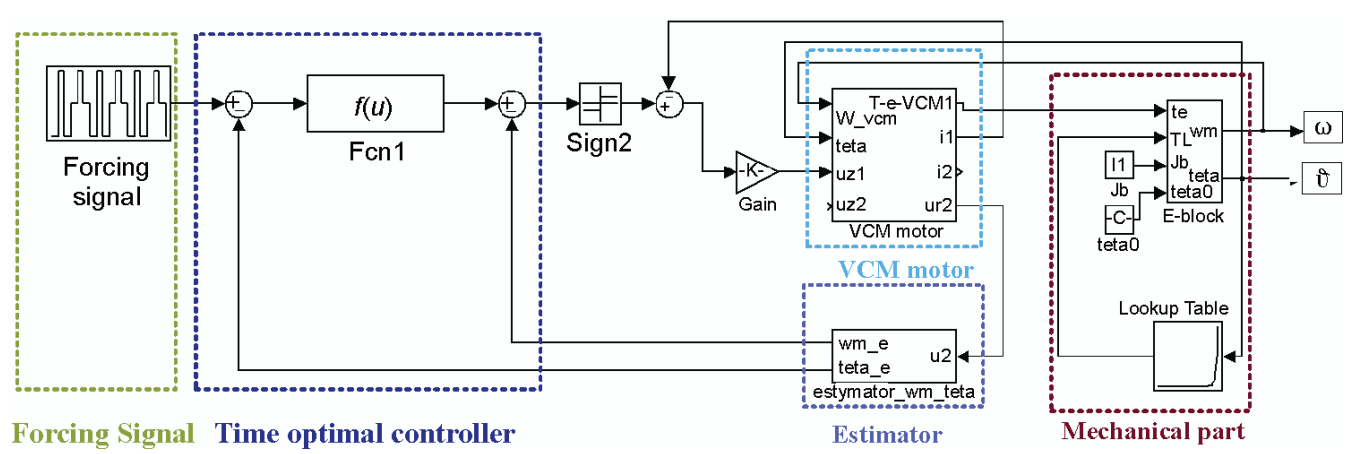

Fig. 13. Implementation of time optimal control of double winding VCM motor

The VCM motor is non-linearity source of the torque in mass storage devices, which results from irregular distribution of magnetic flux density (Fig. 15). This non-linearity affect on induced voltage in second armature results in incorrect estimation of position and velocity of E-block. To avoid this situation, average magnetic induction $B_{\text {averange }}$ was replaced by distribution of magnetic induction approximated by a polynomial of seventh degree (Eq. 8) [9], which coefficients are shown in Table 2.

$$
B(\vartheta)=\mathrm{p}_{7} \vartheta^{7}+\mathrm{p}_{6} \vartheta^{6}+\mathrm{p}_{5} \vartheta^{5}+\mathrm{p}_{4} \vartheta^{4}+\mathrm{p}_{3} \vartheta^{3}+\mathrm{p}_{2} \vartheta^{2}+\mathrm{p}_{1} \vartheta+\mathrm{p}_{0} .
$$


Table 2. Coefficients of Equation 8

\begin{tabular}{c|c}
\hline Coefficients & $\begin{array}{c}\text { Values of } \\
\text { coefficients }\end{array}$ \\
\hline$p_{7}$ & $4.046 \cdot 10^{-11}$ \\
\hline$p_{6}$ & $-7.344 \cdot 10^{-9}$ \\
\hline$p_{5}$ & $4.801 \cdot 10^{-7}$ \\
\hline$p_{4}$ & $-1.596 \cdot 10^{-5}$ \\
\hline$p_{3}$ & 0.000306 \\
\hline$p_{2}$ & -0.003612 \\
\hline$p_{1}$ & 0.02636 \\
\hline$p_{0}$ & 0.66734 \\
\hline
\end{tabular}

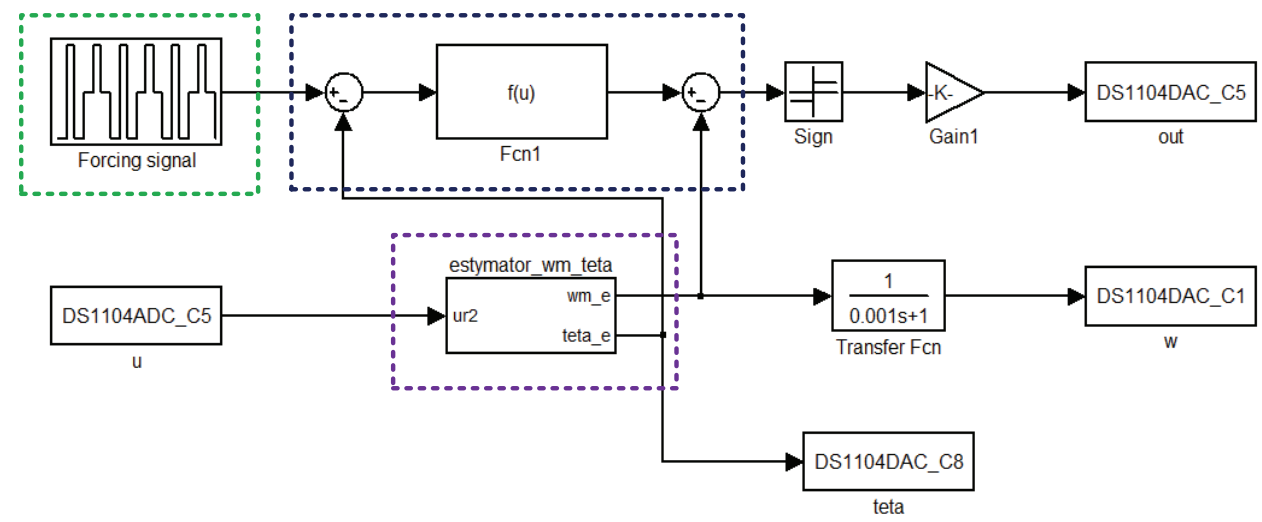

Fig. 14. The controller of time optimal control with estimated position, implemented on the signal processor card dSpace 1104

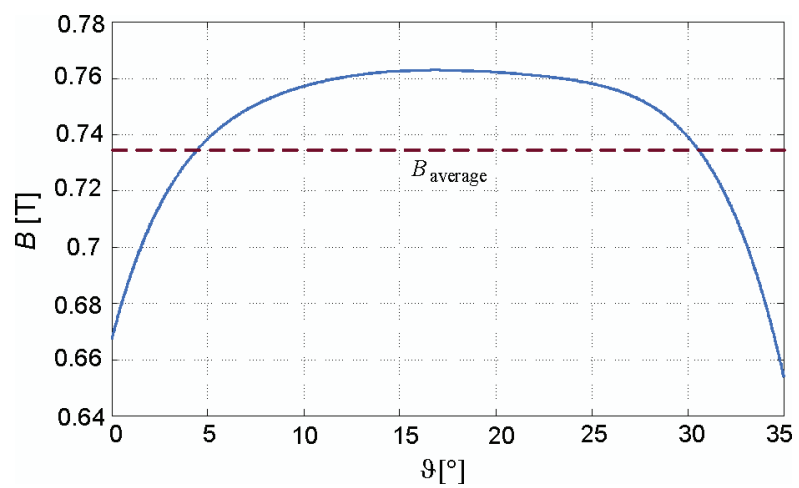

Fig. 15. Blue curve is the distribution of magnetic flux density, red curve is the average magnetic flux density

To investigate the effect of the distribution of magnetic flux density distribution on the positioning accuracy, the "Estimator" block (Fig. 16) was equipped with a switch which 
allows to take into account the magnetic flux density distribution or the average (constant) value $B_{\text {averange }}$ of the distribution of magnetic flux density (Fig. 15, red curve).

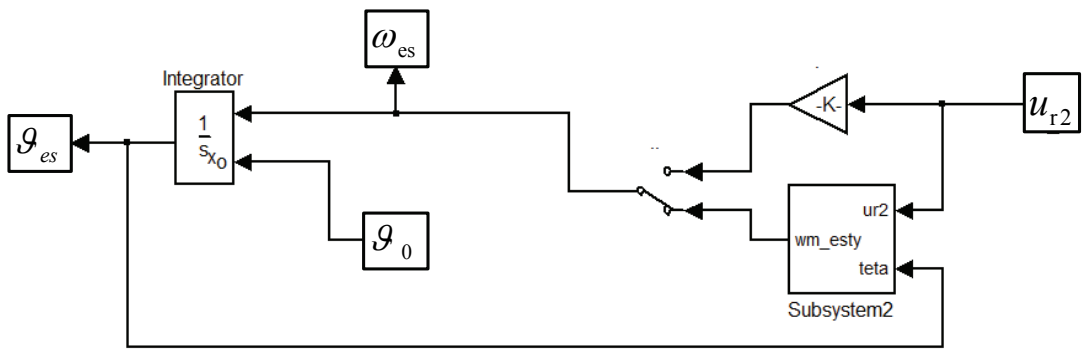

Fig. 16. "Estimator" block

\section{Research results of two winding VCM motor}

The difference between two methods of estimation of angular displacement is shown in Figures 17 and 18. The estimation based on average distribution of magnetic flux density estimates the position of VCM motor with small error only in the middle of motion range. In the extreme position, where magnetic induction decreases, the error rises up and reaches $50 \%$. In Figure 17 the estimated position based on distribution of magnetic flux density is shown (Eq. 8), the red and blue curves are similar in all range of displacement. Control times (displacement from 5 to 30 degrees) compared to the times in table 1 are increased for $5 \mathrm{~ms}$ for estimation with distribution of the magnetic flux density, and for $8 \mathrm{~ms}$ for the estimation with the average magnetic flux density.

Fig 17. Blue curve is the angular displacement estimated basing on the average magnetic flux density, red curve is the real angular displacement measured by laser

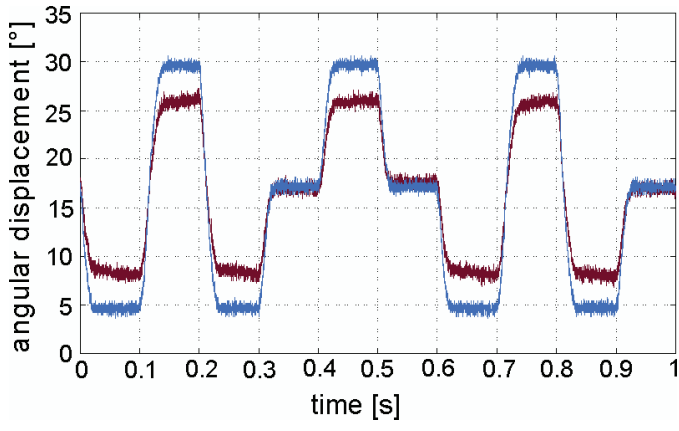

The results of simulation are shown in the Figure 19. As in the case of measurement of angular displacement in simulation estimated angular displacement is less than a real angular displacement. In simulation where estimator takes into account distribution of induction the real and computed angular displacements are the same. 

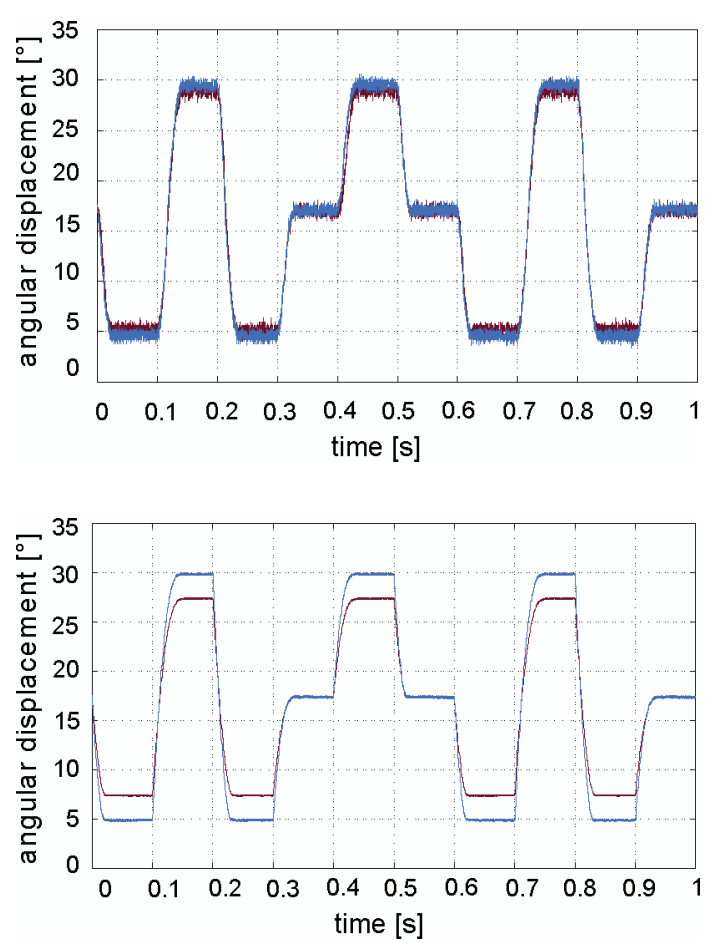

Fig 18. Blue curve is the angular displacement estimated using Eq. 8, red curve is the real angular displacement measured by laser

Fig 19. Blue curve is the angular displacement estimated based on the average magnetic flux density, red curve is the real angular displacement

\section{Conclusion}

In this article the time optimal control of VCM motor, which was implemented on the dSpace signal processors, was presented. The results of measurements were compared with the results obtained by simulations in MATLAB/Simulink environment and summarized in Table 1 . The differences between the measured regulation times and times regulation obtained in the simulation do not exceed $15 \%$, which confirms the validity of the mathematical model of double winding VCM motor.

The sections five and six presents the second variant of time optimal control using the estimator, which calculates the speed and position of the arm of E-block based on voltage induced in the second armature of the motor. Estimated angular displacement was compared with real angular position measured by laser displacement meter. It appeared that estimator calculates well the angular position only in the middle range of the motion. At the extreme angular positions calculated value is overestimated, compared to the measured position of the laser. Estimator calculates the position well only when distribution of magnetic flux density is taken into account.

This article also presents the characteristic for time optimal control triangular shapes of angular speeds, and method how to investigate the correct matched control basing on amplitude of chattering phenomenon. 
This is an extended version of a paper which was presented at the XV Jubileuszowe Sympozjum "Podstawowe Problemy Energoelektroniki, Elektromechaniki i Mechatroniki" PPEEm 2012.

\section{References}

[1] Choe G., Park J., Ikeda Y. et al., Write ability Enhancement in Perpendicular Magnetic Multilayered Oxid. IEEE Transactions on Magnetics 47(1): 55-61 (2011).

[2] Moritz J., Arm C., Vinai G. et al., Two-Bit-Per-Dot Patterned Media for Magnetic Storage. IEEE Magnetics Letters 2 (2011).

[3] Sarajlic E., Yamahata C., Cordero M., Fujita H., Electrostatic rotary stepper micromotor for skew angle compensation in hard disk drive. MEMS 2009 - 22nd IEEE Int. Conf. on Micro Electro Mechanical Systems, pp. 1079-1082 (2009).

[4] Zheng H., Li H., Talke F.E., Numerical Simulation of a Thermal Flying Height Control Slider With Dual Heater and Insulator Elements. IEEE Transactions on Magnetics 45(10): 3628-3631 (2009).

[5] Trawiński T., Wituła R., Modeling of HDD head positioning systems regarded as robot manipulators using block matrices. Robot Manipulators New Achievements, Aleksandar Lazinica and Hiroyuki Kawai (Ed.) INTECH, pp. 129-144 (2010).

[6] Słota D., Trawiński T., Wituła R., Inversion of dynamic matrices of HDD head positioning system. Appl. Math. Model. 35(3): 1497-1505 (2011).

[7] Trawiński T., Kluszczyński K., Kołton W., Lumped parameter model of double armature VCM motor for head positioning system of mass storage devices (in Polish). Electrical Review 87(12b): 184187 (2011).

[8] Trawiński T., Time optimal control of hard disk drive head positioning system (in Polish). Modelowanie $w$ Mechanice. 50 Sympozjon, Ustroń, 2011, Modelowanie Inżynierskie 11(42): 434-440 (2011).

[9] Trawiński T., Mathematical model of voice coil motor with non-smooth magnetic flux density distribution in air-gap (in Polish). Electrical Review 83(12): 114-117 (2007). 